\title{
Outcomes of endoscopic suturectomy with postoperative helmet therapy in bilateral coronal craniosynostosis
}

\author{
S. Alex Rottgers, MD, ${ }^{1}$ Subash Lohani, MD, ${ }^{2}$ and Mark R. Proctor, MD² \\ 1'Department of Plastic and Reconstructive Surgery, Johns Hopkins All Children's Hospital, St. Petersburg, Florida; and \\ 2Department of Neurosurgery, Boston Children's Hospital, Boston, Massachusetts
}

\begin{abstract}
OBJECTIVE Historically, bilateral frontoorbital advancement (FOA) has been the keystone for treatment of turribrachycephaly caused by bilateral coronal synostosis. Early endoscopic suturectomy has become a popular technique for treatment of single-suture synostosis, with acceptable results and minimal perioperative morbidity. Boston Children's Hospital has adopted this method of treating early-presenting cases of bilateral coronal synostosis.

METHODS A retrospective review of patients with bilateral coronal craniosynostosis who were treated with endoscopic suturectomy between 2005 and 2012 was completed. Patients were operated on between 1 and 4 months of age. Hospital records were reviewed for perioperative morbidity, length of stay, head circumference and cephalic indices, and the need for further surgery.

RESULTS Eighteen patients were identified, 8 males and 10 females, with a mean age at surgery of 2.6 months (range 1-4 months). Nine patients had syndromic craniosynostosis. The mean duration of surgery was 73.3 minutes (range 50-93 minutes). The mean blood loss was $40 \mathrm{ml}$ (range 20-100 ml), and 2 patients needed a blood transfusion. The mean duration of hospital stay was 1.2 days (range 1-2 days). There was 1 major complication in the form of a CSF leak. The mean follow-up was 37 months (range 6-102 months). Eleven percent of nonsyndromic patients required a subsequent FOA; $55.6 \%$ of syndromic patients underwent FOA. The head circumference percentiles and cephalic indices improved significantly.
\end{abstract}

CONCLUSIONS Early endoscopic suturectomy successfully treats the majority of patients with bilateral coronal synostosis, and affords a short procedure time, a brief hospital stay, and an expedited recovery. Close follow-up is needed to detect patients who will require a secondary FOA due to progressive suture fusion or resynostosis of the released coronal sutures.

http://thejns.org/doi/abs/10.3171/2016.2.PEDS15693

KEY WORDS syndromic craniosynostosis; endoscopic; minimally invasive; craniofacial

$\mathrm{C}$ RANIOSYNOSTOSIS is the premature fusion of cranial sutures that leads to abnormal head growth. While a single suture is affected in most cases, multisuture synostosis is commonly seen, particularly in patients with an associated syndrome. Bilateral coronal suture fusion is the most common fusion pattern observed in cases of multisuture synostosis. ${ }^{7}$ This fusion pattern results in the development of turribrachycephaly, a skull that is short in the anterior-posterior (AP) dimension (brachycephaly), vertically tall (turricephaly), and widened, and appears to worsen over the 1st year of life..$^{9,16,17}$ It is generally accepted that once turricephaly has developed it is exceedingly difficult to correct. The ideal management of this deformity is early intervention that limits development of turricephaly and facilitates a durable correction of the head shape, mitigating the need for future revision procedures.
Management of multisuture craniosynostosis is also motivated by the potential development of neurological morbidities. Elevations in intracranial pressure (ICP) occur in approximately $14 \%$ of patients with a single suture affected, but those with multiple sutures affected carry a risk of at least $47 \% .{ }^{19}$ Prolonged elevations in ICP may potentially cause blindness and significant cognitive dysfunction. More recently, concerns have been raised that delaying intervention may result in increasing risk of more subtle cognitive deficits. ${ }^{1,8,15}$

Numerous techniques for treating bilateral coronal synostosis have been described, but traditional management has focused on variations of a bilateral frontoorbital advancement (FOA) to increase the AP dimension of the skull and normalize the relationship between the supraorbital rim and the cornea. ${ }^{6,12-14}$ Advancements are

ABBREVIATIONS AP = anterior-posterior; FOA = frontoorbital advancement; ICP = intracranial pressure; ICU = intensive care unit.

SUBMITTED December 10, 2015. ACCEPTED February 29, 2016.

INCLUDE WHEN CITING Published online May 20, 2016; DOI: 10.3171/2016.2.PEDS15693. 
more durable and safer when delayed until after the age of 6 months. ${ }^{20,22,23}$ This delay, however, allows continued development of a turricephalic head shape, which is not treated effectively with an FOA, and exposes the patient to a longer period of cranial growth restriction. Many centers have sought treatment algorithms that allow for earlier intervention to relieve cranial growth restriction and mitigate the development of turricephaly, while preserving the durability and safety achieved with delayed FOA. This has resulted in the current practice of early posterior cranial vault distraction, where enlargement of the unaffected posterior vault is used to increase cranial volume early in an attempt to alleviate elevated ICP and the development of turricephaly. $5,21,24,25,27$ This procedure is then followed by a delayed frontal advancement.

Early removal of the affected cranial suture at 2-4 months of age and guidance of remaining brain growth with either helmet orthoses or spring-assisted cranioplasty have proven effective at correcting the pathologic head shapes seen in single-suture craniosynostosis. ${ }^{2-4,18,26}$ These procedures are less invasive than traditional open cranioplasty and allow safe interventions at an early age. While widely used in cases of single-suture craniosynostosis, only sporadic reports exist of this technique's use in cases of multisuture synostosis. We present a series of patients with bilateral coronal craniosynostosis who were treated successfully with bilateral endoscopic release of the coronal sutures with postoperative helmeting, and we discuss the relevance of this technique as an alternative to other algorithms for management of bilateral coronal craniosynostosis.

\section{Methods}

After institutional review board approval, a retrospective study was conducted of all patients treated at Boston Children's Hospital for bilateral coronal craniosynostosis using an endoscopic suturectomy technique. Patients treated between January 2005 and December 2012 were studied. Electronic medical records were reviewed to obtain patient demographics, cephalic indices, operative outcomes, and complications. All surgical procedures had been performed by the senior author (M.R.P.).

\section{Evaluation}

Patients had been evaluated in the craniofacial clinic by both the neurosurgical and plastic surgical teams. All patients underwent full clinical examination, including measurements of head circumference and the AP and lateral dimensions to calculate the cephalic index. Radiographic studies included CT scanning to confirm the clinical diagnosis. Upon review of the charts, pre- and postoperative anthropometric values were compared statistically using the Wilcoxon signed-rank test with a 2-tailed hypothesis.

Patients presenting prior to 5 months of age were offered treatment with either endoscopic suturectomy and helmet therapy or the open FOA. Patients who presented after 5 months of age were offered the open procedure. Those with significant cranial deformities with excessive thumbprinting and projection of bony spicules into the sulci of the brain were not considered candidates for an endoscopic approach because of the increased risk for dural tears and the development of a CSF leak. These patients were offered open surgery. A clinical geneticist evaluated all patients, and the appropriate genetic testing was completed. Secondary surgery was considered in patients who postoperatively developed symptoms involving increasing ICP, declining cranial growth noted on their growth chart, and/or worsening cranial morphology with increasing supraorbital retrusion. Secondary suture fusion on imaging was correlated with the clinical picture. Radiographic fusion without evidence of growth restriction or symptomatology was followed clinically. Secondary fusion in the setting of elevated ICP and restricted growth was considered an indication for secondary FOA. Postoperative CT scans were not routinely obtained unless clinically indicated. Studies were carried out to investigate declining head growth, changes in cranial shape, persistent cranial defects, or signs and symptoms of increased ICP.

\section{Procedure}

All operations were performed with the patient in the supine position under general anesthesia. Bilateral, $2-\mathrm{cm}$ incisions were made overlying the fused coronal sutures, halfway between the anterior fontanel and the level of the lateral canthus. Incisions were perpendicular to the suture and were made using Colorado needle tip Bovie cautery through the skin, galea, and periosteum. A periosteal tunnel was begun using an elevator along the fused suture. A single bur hole was made along the fused suture using a high-speed drill and acorn bur. This was sequentially enlarged with a curette and Kerrison rongeurs. Dura and periosteum were stripped linearly along the fused suture, medially to the fontanel, and laterally toward the skull base. Kerrison rongeurs and Tessier bone cutting scissors were used to create a 1-cm-wide craniectomy. At the end of the medial and lateral dissection, a lighted endoscope was used to transilluminate the skull and scalp to confirm the location as well as to aid in direct visualization before completing the craniectomy.

In coronal synostosis, the sphenoid wing and coronal suture are pathologically displaced anteriorly toward the lateral orbit. The craniectomy follows the fused suture laterally, halfway to the cranial base. The path of bony excision then continues straight inferiorly until the skull base is reached. The trajectory of the inferior ostectomy is, therefore, posterior to the pathologic suture, which turns anteriorly toward the lateral canthus. The strip craniectomy is completed at the inferior aspect of the squamosal temporal bone (Fig. 1B and D). Once the medial and lateral excisions are completed, the frontal and parietal bones become mobile. This can be confirmed with bimanual ballottement. The strip craniectomy is filled with Gelfoam soaked in thrombin and irrigated with bacitracin. An identical procedure is completed on the contralateral side. Incisions are closed in 2 layers with absorbable sutures.

\section{Postoperative Care}

Patients were routinely admitted to the floor for 23-hour observation unless there was concern for airway stability, for which management in the intensive care unit (ICU) was indicated. Discharge was routinely on the 1st postop- 

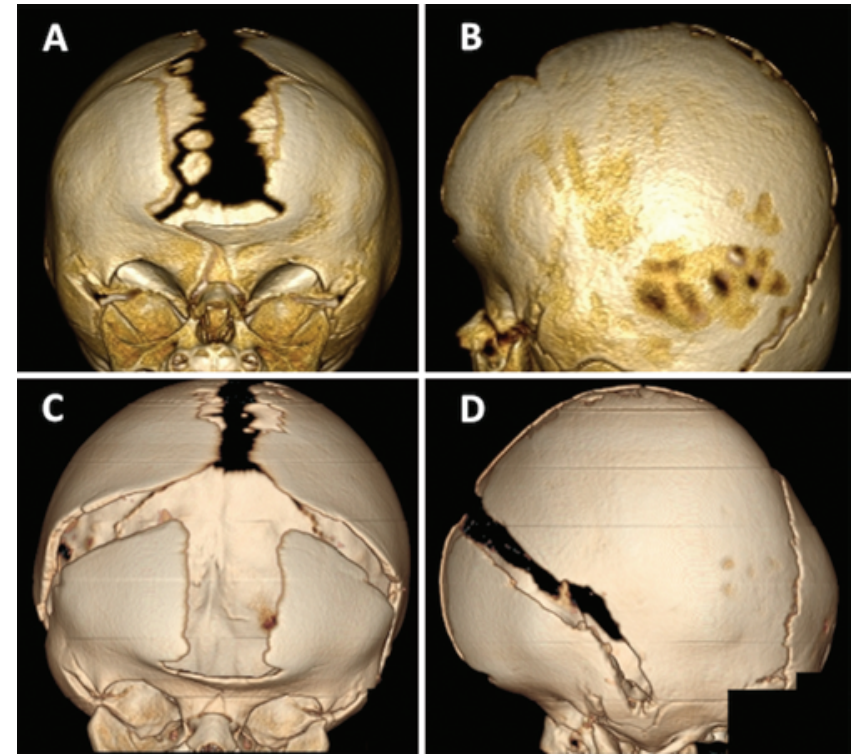

FIG. 1. 3D reconstructions of preoperative ( $A$ and $B$ ) and postoperative (C and D) CT scans obtained in a patient with Apert syndrome treated with bilateral coronal suturectomy. The follow-up imaging was obtained after the patient presented with a pseudomeningocele 1 month after surgery. The images demonstrate the correct trajectory for suturectomy and the full release of the frontal bone to the level of the cranial base and lateral canthus. Figure is available in color online only.

erative day. Patients were fitted for orthotic helmets approximately 1 week after surgery. To allow for 3D growth, helmets were designed to contact all areas of the cranium excluding areas of desirable growth. Patients were advised to wear helmets for 23 hours a day. Patients were followed up at regular intervals in the craniofacial clinic. Helmets were discontinued once the head shape was normalized or the patient reached 1 year of age.

\section{Results}

In total, 18 patients with bilateral coronal craniosynostosis (8 males and 10 females; male/female ratio 1:1.25) were treated with endoscopic suturectomy between 2005 and 2012. Nine cases had genetic test-proven syndromic association: 3 Saethre-Chotzen, 2 Apert, 3 Muenke, and 1 Pfeiffer syndrome. The other 9 patients had presumed nonsyndromic bilateral coronal craniosynostosis. One patient had associated metopic synostosis at the time of presentation, which was managed with concurrent endoscopic metopic suture suturectomy at the time of coronal suturectomy.

CT scanning was performed for diagnostic confirmation in all patients prior to surgery. The mean age at surgery was 2.6 months (range 1-4 months). The mean duration of surgery was 73.3 minutes (range 50-93 minutes), and the mean blood loss was $40 \mathrm{ml}$ (range $20-100 \mathrm{ml}$ ). The mean preoperative hematocrit was $33.8 \%$ (range $27.7 \%-43.5 \%$ ), and the mean postoperative hematocrit was $24.3 \%$ (range $17.9 \%-33 \%)$. The hematocrit was always checked prior to surgery and within 2 hours of completion of surgery. If the postsurgical hematocrit was greater than $20 \%$ and it was felt there was no significant intraoperative bleeding, it was not rechecked again unless there was a clinical con- cern for hypovolemia. If the hematocrit was between $18 \%$ and $20 \%$, it was rechecked later that day or the following morning, but a further drop was rarely seen. If it was less than $18 \%$, a transfusion of $15 \mathrm{ml}$ packed red blood cells $/ \mathrm{kg}$ was generally administered. Two patients (11.1\%) needed blood transfusion: one was a 1-month-old male with $50 \mathrm{ml}$ of blood loss, and the other was a 4-month-old male with $100 \mathrm{ml}$ of blood loss during the procedure. Three patients (16.7\%) were admitted to the ICU for respiratory concerns related to their syndromic diagnosis. All other patients were admitted to the floor. The mean duration of hospital stay was 1.2 days (range 1-2 days).

\section{Complications}

One minor and 1 major complication occurred in this series. The minor complication required readmission within 7 days: the patient was admitted with decreased appetite and vomiting, which was deemed to be due to viral gastroenteritis. The patient had an uneventful hospital stay and was discharged after 4 days. The other patient was a 4-month-old male with Apert syndrome, without evidence of elevated ICP preoperatively. He presented to clinic 1 month postoperatively with a pseudomeningocele and CSF leakage from his incision. The original surgery had been complicated by a dural tear at the bur hole site directly under the incision, which had been primarily repaired. Due to early signs of pseudomeningocele, the patient was taken to the operating room for wound revision and lumbar drain placement. There was good access to the site from the existing incision but thin dura that ultimately did not respond well to primary repair. The patient presented again 2 weeks later with a recurrent pseudomeningocele. It was felt that a more formal opening of the dura and placement of a patch without tension would be necessary. A third operation including dural patch, lumbar drain placement, and formal FOA was performed without subsequent issues.

\section{Outcomes}

The mean clinical follow-up was 37 months (range 6-102 months). Six patients (33\%) were recommended to undergo a secondary FOA due to slowed cranial growth and symptoms suggestive of intracranial hypertension despite good improvement in morphology. Five patients underwent this operation. One (11\%) of the 9 nonsyndromic patients required a secondary FOA, and $5(56 \%)$ of the 9 syndromic patients underwent or were recommended to undergo a secondary FOA. One of these procedures was for management of a postoperative CSF leak, as described above. Fifty percent ( 4 of 8 ) of the remaining syndromic patients required a secondary FOA. Secondary FOAs were performed, on average, 15 months (range 1.1-22.7 months) following the endoscopic release.

Changes in head circumference, head circumference percentile, and cephalic index were documented. These were further subdivided into those patients who required a secondary FOA and those who did not. Anthropometric follow-up data were available for 28 months (range 6.471.6 months) after initial release in patients who did not undergo FOA. For patients needing an FOA, this follow-up was only 12.4 months (range 1.5-17.8 months) because the 
final measurement was taken prior to this operation. The mean head circumference for the entire cohort increased from $35.8 \mathrm{~cm}$ to $47.5 \mathrm{~cm}(\mathrm{p}=0.002)$. Significant increases in head circumferences were observed in all patients; however, those patients requiring a subsequent FOA were noted to have a fall-off in head circumference percentile despite positive overall head growth (Fig. 2). This increase was not statistically significant for the entire cohort $(\mathrm{p}=$ 0.09). Patients treated successfully without FOA showed a significant improvement in mean percentile, from the 30.3 rd percentile (range 1st-50th percentile) to the 46.9th percentile (range 10th-90th percentile) $(\mathrm{p}=0.025)$. The patients requiring an FOA demonstrated a nonsignificant decrease in head circumference percentile just prior to FOA. These patients universally showed improvement of their head size shortly after release, but growth leveled off after the fusion of additional sutures or refusion of the released coronal sutures.

Cephalic indices improved significantly in the whole cohort for both the FOA and non-FOA subgroups (Fig. 3). Preoperatively, the mean cephalic index for the entire cohort was 0.94 (0.84-1.0). This improved to a postoperative cephalic index of $0.84(0.78-0.93)$. Patients treated without FOA improved from 0.97 (0.89-1.0) to 0.84 (0.78$0.93)$. Those who ultimately required FOA showed a similar trend, with less severe morphology prior to the FOA. The mean preoperative cephalic index was $0.92(0.84-1.0)$ and the postoperative value was $0.84(0.80-0.88)$. The improved head shape in the FOA group reflects the early success of their operation followed by subsequent growth restriction after a second fusion event.

Eleven patients underwent follow-up CT scanning at mean postoperative intervals of 13.4 months (range 1-26 months) (Fig. 1). Follow-up scans showed asymptomatic lambdoid suture fusion in 1 patient, isolated sagittal fusion in 1 patient, sagittal synostosis along with coronal refusion in 2 patients, and isolated coronal refusion in 4 patients.

\section{Discussion}

Early endoscopic suturectomy has become an accepted treatment for single-suture craniosynostosis, particularly sagittal synostosis. Postoperative helmet therapy, springassisted cranioplasty, or cranial distraction must be used to maintain patency of the released suture and to guide subsequent growth..$^{2-4,18,26}$ These strategies have been applied to the other cranial sutures with success, and a limited number of experiences with nonsyndromic multisuture synostosis cases have been reported.,11 Jimenez and Barone have recently reported on the successful early management of a patient with Apert syndrome using this technique. ${ }^{10}$ Based on these experiences, our center has begun to employ a strategy of bilateral endoscopic coronal suturectomy for the management of syndromic and nonsyndromic cases of bilateral coronal synostosis.

Minimally invasive, suturectomy offers many advantages over conventional cranial vault remodeling and FOA techniques. The minimally invasive procedures are associated with shorter operative times, fewer ICU admissions, shorter length of hospital stay, less blood loss, and fewer transfusions. Though this report does not include a direct

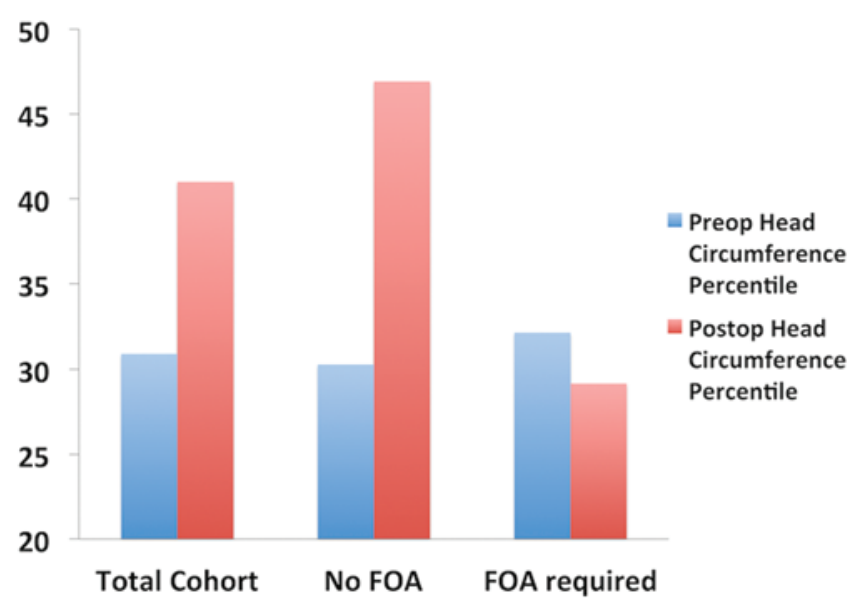

FIG. 2. Bar graph showing pre- and postoperative head circumference percentiles. The mean head circumference percentile for the entire cohort increased over the treatment period from the 30.9th percentile (range 1st-75th percentile) to the 41st percentile (range 2nd-90th percentile). This change was not statistically significant $(p=0.09)$. Those patients treated successfully without an FOA showed a significant improvement from the $30.3 \mathrm{rd}$ percentile (range 1st-50th percentile) to the 46.9 th percentile (range 10 th-90th percentile) $(p=0.025)$. Those patients requiring an FOA showed a decrease in head percentile from the $32.2 n d$ percentile (range $2 n d-75$ th percentile) to the $29.2 n d$ percentile (range 2nd-61st percentile). This was not significant ( $p>0.05, W$ value $=9$ ). Final measurements were taken of the FOA patients prior to this procedure. Figure is available in color online only.

comparison with open cranial procedures, the same benefits can be seen in our results, with a mean operative time of 73 minutes, $11.1 \%$ transfusion rate, $16.6 \%$ ICU admission rate, and a mean hospital stay of 1.2 days. This safety profile is superior to that for posterior distraction., ${ }^{912,25}$

Careful patient selection is also important for success. Preoperative CT allows for the detection of multiple suture fusion events, elevated ICP, and thumbprinting of the cranium. Patients with significant loss of bone stock and thumbprinting due to pancraniosynostosis would likely respond better to an open release of the entire cranium. Multiple interstices and bone spicules caused by elevated ICP predispose to the creation of dural tears during bone removal. This is illustrated in our study by the case involving the patient with Apert syndrome whose postoperative CSF leak ultimately required a formal FOA to allow access and decompression for the repair to succeed.

Preoperative counseling and postoperative surveillance are key to successfully utilizing this method of treating bilateral coronal craniosynostosis. This technique is not a replacement for FOA in all patients. Subsequent fusion of additional sutures, progressive postnatal pansynostosis, or refusion of the coronal sutures may occur in syndromic patients and in patients who likely harbor a currently unknown genetic aberration but have tested negative on routine panels. These events have caused patients to respond well early, following their release and course of helmeting, but subsequently exhibit growth restriction. This is demonstrated in our data. Both the patients that required and those that did not require a secondary FOA achieved the same ultimate cephalic index (Fig. 3). The release of the affected sutures allowed rapid head growth and normalization of head morphology with use of the helmet. 


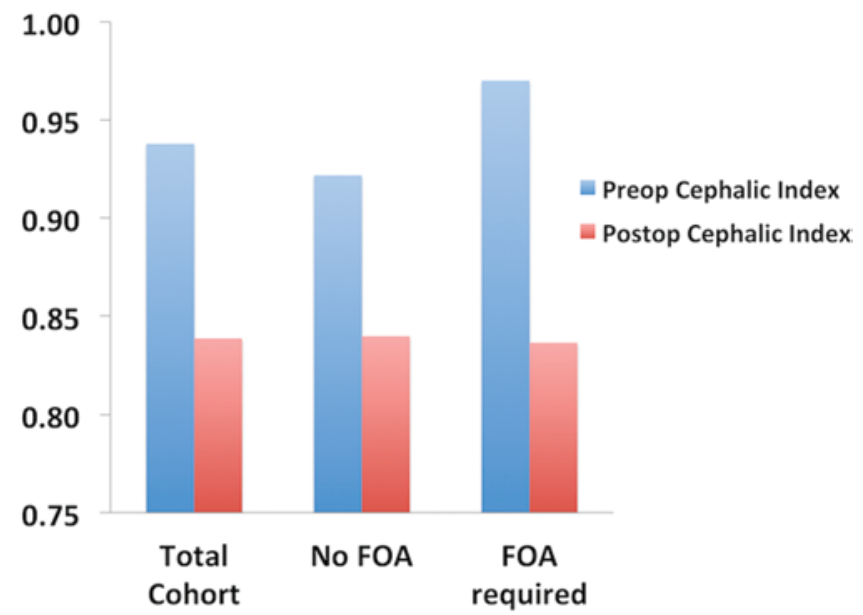

FIG. 3. Bar graph showing pre- and postoperative cephalic indices. The entire cohort showed a significant improvement in the mean cephalic index during the treatment course from 0.94 (range 0.84-1) to 0.84 (range $0.78-0.93)(p=0.003)$. Those patients treated successfully without an FOA improved from 0.92 (range 0.84-1) to 0.84 (range 0.78-0.88) (p $=0.003$ ). Patients requiring a secondary FOA improved as well, from 0.97 (range $0.89-1$ ) to 0.84 (range $0.78-0.93)(p<0.05$ ). Final measurements were taken of the FOA patients prior to this procedure. Figure is available in color online only.

Secondary fusion events and genetically programmed diminished growth resulted in subsequent restriction that developed in the late 1st and early 2 nd postoperative year. Radiographic obliteration of sutures was not seen as an indication for reoperation alone. These findings were correlated with cranial morphology, growth, and behavior to determine which patients required further surgery. These events are more common in syndromic patients but can occur in both patient groups. Eleven percent of nonsyndromic patients and $50 \%$ of syndromic patients required an FOA for suture refusion. These events occurred within the 1st year after release and were detectable by development of an abnormal head shape or deviation from the previous head circumference growth curve. It is critical to counsel parents preoperatively to inform them that a second operation may be required and that regular follow-up with dilated funduscopic examination and head circumference measurements is essential.

A majority of patients in our series were successfully managed with a single operation. This does not represent a panacea for treating bilateral coronal craniosynostosis, as a second operation is needed in $33 \%$ of patients, and our patients have not yet reached skeletal maturity. Parents should be counseled that a second operation may be warranted for progressive pancraniosynostosis and refusion or to improve cosmetic outcomes. Other centers have strongly advocated the use of early posterior cranial vault distraction followed by an FOA in bilateral coronal craniosynostosis, and they cite the benefits of early release of cranial restriction and improved morphology due to the cessation of the development of turricephaly. $5,21,24,25,27$ Similarly, endoscopic suture release allows safe, early release of restricted cranial growth but addresses the site of pathology directly. This treatment therefore offers the patient the chance of treatment with a single operation and avoids an algorithm that requires 3 operations (osteotomy and device placement, device removal, and ultimate FOA). Compared with this, endoscopic suturectomy and helmet therapy is an attractive alternative. Delayed intervention with a single FOA late in the 1st year of life is a viable option, but this exposes the patient to continued restriction during the phase of fastest brain growth and may contribute to the continued development of turricephaly, which is difficult to correct secondarily. Future directions should include the development of metrics to quantify the change in head shape seen in these patients.

\section{Conclusions}

Bilateral endoscopic suturectomy with postoperative helmet therapy is a successful method for treating bilateral coronal craniosynostosis. It results in both improved cranial volume and head shape as measured with head circumference and cephalic indices. Postoperative monitoring for suture refusion and progressive pancraniosynostosis is essential, notwithstanding our findings that $67 \%$ of patients have not required a secondary procedure within a mean follow-up greater than 3 years. When compared with other means of early intervention such as posterior vault distraction, the safety profile of bilateral suturectomy is superior and requires fewer operative interventions.

\section{References}

1. Arnaud E, Meneses P, Lajeunie E, Thorne JA, Marchac D, Renier D: Postoperative mental and morphological outcome for nonsyndromic brachycephaly. Plast Reconstr Surg 110:6-13, 2002

2. Barone CM, Jimenez DF: Endoscopic craniectomy for early correction of craniosynostosis. Plast Reconstr Surg 104:1965-1975, 1999

3. Berry-Candelario J, Ridgway EB, Grondin RT, Rogers GF, Proctor MR: Endoscope-assisted strip craniectomy and postoperative helmet therapy for treatment of craniosynostosis. Neurosurg Focus 31(2):E5, 2011

4. David LR, Plikaitis CM, Couture D, Glazier SS, Argenta LC: Outcome analysis of our first 75 spring-assisted surgeries for scaphocephaly. J Craniofac Surg 21:3-9, 2010

5. Derderian CA, Bastidas N, Bartlett SP: Posterior cranial vault expansion using distraction osteogenesis. Childs Nerv Syst 28:1551-1556, 2012

6. Fearon JA: Beyond the bandeau: 4 variations on fronto-orbital advancements. J Craniofac Surg 19:1180-1182, 2008

7. Fearon JA: Syndromic craniosynostosis, in Neligan PC (ed): Plastic Surgery, ed 3. Philadelphia: Saunders Elsevier, 2012, Vol 3, pp 749-760

8. Fok H, Jones BM, Gault DG, Andar U, Hayward R: Relationship between intracranial pressure and intracranial volume in craniosynostosis. Br J Plast Surg 45:394-397, 1992

9. Goldstein JA, Paliga JT, Wink JD, Low DW, Bartlett SP, Taylor JA: A craniometric analysis of posterior cranial vault distraction osteogenesis. Plast Reconstr Surg 131:1367-1375, 2013

10. Jimenez DF, Barone CM: Bilateral endoscopic craniectomies in the treatment of an infant with Apert syndrome. J Neurosurg Pediatr 10:310-314, 2012

11. Jimenez DF, Barone CM: Multiple-suture nonsyndromic craniosynostosis: early and effective management using endoscopic techniques. J Neurosurg Pediatr 5:223-231, 2010

12. Koh KS, Kang MH, Yu SC, Park SH, Ra YS: Treatment of nonsyndromic bilateral coronal synostosis using a multiple 
bone flap rotation-reposition technique. J Craniofac Surg 15:603-608, 2004

13. Marchac D, Renier D, Jones BM: Experience with the "floating forehead.” Br J Plast Surg 41:1-15, 1988

14. Mulliken JB, Godwin SL, Pracharktam N, Altobelli DE: The concept of the sagittal orbital-globe relationship in craniofacial surgery. Plast Reconstr Surg 97:700-706, 1996

15. Patel A, Yang JF, Hashim PW, Travieso R, Terner J, Mayes LC, et al: The impact of age at surgery on long-term neuropsychological outcomes in sagittal craniosynostosis. Plast Reconstr Surg 134:608e-617e, 2014

16. Posnick JC, Lin KY, Jhawar BJ, Armstrong D: Apert syndrome: quantitative assessment by $\mathrm{CT}$ scan of presenting deformity and surgical results after first-stage reconstruction. Plast Reconstr Surg 93:489-497, 1994

17. Posnick JC, Lin KY, Jhawar BJ, Armstrong D: Crouzon syndrome: quantitative assessment of presenting deformity and surgical results based on CT scans. Plast Reconstr Surg 92:1027-1037, 1993

18. Pyle J, Glazier S, Couture D, Sanger C, Gordon S, David L: Spring-assisted surgery-a surgeon's manual for the manufacture and utilization of springs in craniofacial surgery. $\mathbf{J}$ Craniofac Surg 20:1962-1968, 2009

19. Renier D, Sainte-Rose C, Marchac D, Hirsch JF: Intracranial pressure in craniostenosis. J Neurosurg 57:370-377, 1982

20. Selber JC, Brooks C, Kurichi JE, Temmen T, Sonnad SS, Whitaker LA: Long-term results following fronto-orbital reconstruction in nonsyndromic unicoronal synostosis. Plast Reconstr Surg 121:251e-260e, 2008

21. Steinbacher DM, Skirpan J, Puchała J, Bartlett SP: Expansion of the posterior cranial vault using distraction osteogenesis. Plast Reconstr Surg 127:792-801, 2011

22. Wagner JD, Cohen SR, Maher H, Dauser RC, Newman MH: Critical analysis of results of craniofacial surgery for nonsyndromic bicoronal synostosis. J Craniofac Surg 6:32-39, 1995

23. Wall SA, Goldin JH, Hockley AD, Wake MJ, Poole MD, Briggs M: Fronto-orbital re-operation in craniosynostosis. Br J Plast Surg 47:180-184, 1994

24. White N, Evans M, Dover MS, Noons P, Solanki G, Nishikawa $\mathrm{H}$ : Posterior calvarial vault expansion using distraction osteogenesis. Childs Nerv Syst 25:231-236, 2009
25. Wiberg A, Magdum S, Richards PG, Jayamohan J, Wall SA, Johnson D: Posterior calvarial distraction in craniosynostosis-an evolving technique. J Craniomaxillofac Surg 40:799-806, 2012

26. Windh P, Davis C, Sanger C, Sahlin P, Lauritzen C: Springassisted cranioplasty vs pi-plasty for sagittal synostosis - a long term follow-up study. J Craniofac Surg 19:59-64, 2008

27. Ylikontiola LP, Sándor GK, Salokorpi N, Serlo WS: Experience with craniosynostosis treatment using posterior cranial vault distraction osteogenesis. Ann Maxillofac Surg 2:4-7, 2012

\section{Disclosures}

The authors report no conflict of interest concerning the materials or methods used in this study or the findings specified in this paper.

\section{Author Contributions}

Conception and design: all authors. Acquisition of data: all authors. Analysis and interpretation of data: Rottgers. Drafting the article: Rottgers, Lohani. Critically revising the article: Proctor, Rottgers. Reviewed submitted version of manuscript: Rottgers, Lohani. Approved the final version of the manuscript on behalf of all authors: Proctor. Statistical analysis: Rottgers. Study supervision: Proctor.

\section{Supplemental Information \\ Previous Presentations}

Portions of this paper were presented at the 15th Biennial Congress of the International Society of Craniofacial Surgeons (September 10-14, 2013, in Jackson Hole, Wyoming).

\section{Correspondence}

Mark R. Proctor, Department of Neurosurgery, Boston Children's Hospital, 300 Longwood Ave., Boston, MA 02115. email: mark. proctor@childrens.harvard.edu. 